\title{
PASAPORTES DECIMONÓNICOS FRANCESES
}

\section{$19^{\text {TH }}$ CENTURY FRENCH PASSPORTS}

\author{
JUAN CARLOS GALENDE DÍAZ \\ NICOLÁS ÁVILA SEOANE \\ Universidad Complutense de Madrid
}

\begin{abstract}
Resumen: Revisamos en este trabajo la legislación francesa sobre pasaportes dictada desde la Revolución hasta la caída de la Monarquía de Julio, fijándonos en particular en los aspectos relacionados con la Paleografía y la Diplomática: caracteres externos, tipografía, formulario, elementos de validación, visados..., antes de entrar en el estudio de dos ejemplares conservados en los archivos municipales de Toledo y Escalona.
\end{abstract}

Palabras clave: Pasaportes, Paleografía, Diplomática, Francia, siglo XIX.

\begin{abstract}
This paper reviews the French legislation about passports issued from the Revolution to the fall of the July Monarchy. We focus on the aspects related with Palaeography and Diplomatics: external characters, typography, form, validation elements, visas... Immediately after we study two specimens preserved in the municipal archives of Toledo and Escalona.
\end{abstract}

Keywords: Passports, Palaeography, Diplomatics, France, $19^{\text {th }}$ century.

\section{INTRODUCCIÓN.}

Aun sin ser muy habitual, son varios los archivos municipales españoles que conservan pasaportes de transeúntes extranjeros. No olvidemos que era a las autoridades concejiles a quienes competía no sólo revisarlos en cada lugar de pernocta, sino también retenerlos una vez alcanzado el destino ${ }^{1}$.

Es el caso de dos ejemplares franceses hallados en los archivos de Toledo y Escalona, uno del reinado de Luis Felipe y otro de la II República ${ }^{2}$. El primero fue expedido en Toulouse el 21 de junio de 1836 a nombre de Jean Pierre Martin Duffour, de 33 años, cuya profesión, en esta oportunidad, anormalmente, no consta ${ }^{3}$,

${ }^{1}$ J. C. GALENDE DÍAZ, "Fuentes onomásticas: el pasaporte como documento inspector e identificativo personal en el Antiguo Régimen”, en C. MAÍZ ARÉVALO (ed.), Nombre propio e identidad cultural, Madrid, 2010, pp. 40-41.

${ }^{2}$ Damos las gracias a D. Mariano García Ruipérez y a Da. Rosa María Vilas Ruiz por dejarnos consultar los fondos a su cargo y por su valiosa ayuda.

${ }^{3}$ Archivo Municipal de Toledo, caja 6083. 
y el segundo, el 30 de julio de 1852 en la embajada de Madrid en favor de Joseph Viala, de 23 años, que era marchand d'estampes, o bien avaniquero según el funcionario de Escalona que lo inscribió en el registro ${ }^{4}$. Ambos viajeros procedían de Couret, municipio del departamento del Alto Garona, situado apenas veinticinco kilómetros al norte del valle de Arán.

En nuestro país hasta hace muy poco apenas se había abordado el estudio diplomático de los pasaportes, tanto foráneos como propios ${ }^{5}$. Y en Francia, aunque la bibliografía es anterior y más copiosa, se echan igualmente en falta trabajos específicos ${ }^{6}$. Para paliar tal carencia conviene consultar detenidamente la producción legislativa del período y a ello dedicaremos enseguida un extenso apartado.

El étimo de pasaporte es precisamente francés ${ }^{7}$, acreditado ya en el siglo $\mathrm{XV}^{8}$. Figura en el Dictionnaire de l'Académie française desde su primera edición (París, 1694): “ordre par escrit donné par le souverain, ou par celuy qui a pouvoir de luy, pour la liberté et la seureté du passage des personnes, des hardes, des mar-

\footnotetext{
${ }^{4}$ Archivo Histórico Municipal de Escalona, Gobierno, Pasaportes y licencias, legajo 1.

${ }^{5}$ Destacan en particular las obras del profesor Galende, de cuyas notas a pie de página pueden extraerse algunos otros títulos: J. C. GALENDE DÍAZ y M. GARCÍA RUIPÉREZ, "Los pasaportes en España durante el Trienio Liberal. Análisis archivístico y diplomático", en VII Congreso internacional de Historia de la Cultura escrita, Alcalá de Henares, 2004, pp. 219-233, y "Los pasaportes, pases y otros documentos de control e identidad personal en España durante la primera mitad del siglo XIX. Estudio archivístico y diplomático”, Hidalguía, 302 (2004), pp. 113144, y 303 (2004), pp. 169-208; J. C. GALENDE DÍAZ, "El pasaporte militar desde una perspectiva diplomatista (1700-1850)", en III Jornadas de la Sociedad Española de Ciencias y Técnicas Historiográficas. Diplomática antigua. Diplomática moderna, Murcia, 2006, pp. 303318, y "Fuentes onomásticas: el pasaporte como documento...", pp. 29-55, y J. C. GALENDE DÍAZ y N. ÁVILA SEOANE, "De Nápoles a Toledo, un reiterado periplo visado en pasaportes decimonónicos", Archivi, en prensa.

${ }^{6}$ J. B. BONET DE TREYCHES, Vues nouvelles sur les passe-ports, París, 1806; A. SÉE, Le passeport en France, Chartres, 1907; L. MÉROC, Faux passeports, faux permis de chasse et faux assimilés, Toulouse, 1930; M. D'HARTOY, Histoire des passeports français depuis l'Antiquité jusqu'à nos jours: histoire législative et doctrinale, analyse et critique, renseignements pratiques, París, 1937; D. NORDMAN, "Sauf-conduits et passeports en France à la Renaissance", en J. CÉARD y J. C. MARGOLIN (dirs.), Voyager à la Renaissance, París, 1987, pp. 145-158; G. NOIRIEL, "Surveiller les déplacements ou identifier les personnes? Contribution à l'histoire du passeport en France de la Ire à la III ${ }^{\mathrm{e}}$ République", Genèses, 30 (1998), pp. 77-100; P. PIAZZA, Histoire de la carte nationale d'identité, París, 2004, o M. BORDIGONI, “"Vos papiers, s'il vous plaît»: invention des identités de papiers et imposition des papiers d'identité en France et dans les colonies", en K. CHACHOUA (dir.), Actes du colloque L'émigration algérienne en France. Un cas exemplaire, Argel, 2012, pp. 371-389.

7 J. COROMINAS Y VIGNEAUX y J. A. PASCUAL RODRÍGUEZ, Diccionario crítico etimológico castellano e hispánico, vol. IV, Madrid, 1981, bajo pasar.

${ }^{8}$ J. DUBOIS, H. MITTERAND y A. DAUZAT, Dictionnaire d'étymologie, Montreal, 2001, voz passer.
} 
chandises, et cetera"9. La de 1740 actualiza la ortografía pero apenas introduce cambios: "ordre par écrit donné par le souverain, ou en son nom, pour la liberté et la sûreté du passage des personnes, des hardes, des marchandises, et cetera" ${ }^{10}$.

En 1835 la II República elude mencionar al souverain: “ordre par écrit donné par les autorités compétentes pour la liberté et la sûreté du passage des personnes, des effets, des marchandises, et cetera". La séptima edición, de 1878, eliminó el guión entre las dos partes de la palabra y restringió el significado del término al tránsito exclusivo de personas: “ordre par écrit donné par les autorités compétentes pour la liberté et la sûreté des personnes qui en sont munies".

La octava, editada entre 1932 y 1935 , ya especifica que habitualmente se trata de permisos de salida al extranjero: “pièce d'identité délivrée par l'État permettant aux nationaux d'un pays soit de circuler librement à l'intérieur soit de voyager dans un autre pays. [...] Il est surtout usité pour les voyages à l'étranger. Pour la circulation à l'intérieur on dit plutôt sauf-conduit'. El actual Dictionnaire incorpora ya plenamente ese sentido a su principal acepción, si bien mantiene una referencia a los de ámbito interior: "composé de passe, forme conjuguée de passer, et de port, au sens de 'passage, chemin'. Document délivré par l'État qui, certifiant l'identité, la nationalité et le domicile de son titulaire, permet à celui-ci de pénétrer dans un pays étranger. [...] Désigne aussi un document similaire nécessaire pour voyages à l'intérieur d'un pays"11.

\section{LEGISLACIÓN FRANCESA HASTA MEDIAR EL SIGLO XIX. \\ 2.1. Los pasaportes de la Revolución (1789-1799).}

Durante el Antiguo Régimen el pasaporte había servido en Francia para facilitar tanto la salida de comerciantes al extranjero, como la repatriación forzosa de vagabundos, pero también, según acabamos de constatar en las definiciones académicas, lo podían exigir dentro del propio país las diferentes autoridades, ya fueran estatales, municipales o incluso gremiales ${ }^{12}$. La Revolución Francesa su-

\footnotetext{
${ }^{9} \mathrm{Y}$ así lo calca la segunda edición, de 1718, titulada Nouveau dictionnaire de l'Académie française.

${ }^{10}$ Repetido al pie de la letra en 1762 (cuarta edición) y 1798 (quinta).

${ }^{11}$ Dictionnaire de l'Académie française, $9^{a}$ edición en preparación, voz publicada en Journal officiel de la République Française. Édition des documents administratifs, 2006, núm. 10, p. 26.

${ }^{12}$ Véase al respecto M. D’HARTOY, Histoire des passeports français..., pp. 31-38. En las pp. 39-66 analiza desde un punto de vista jurídico las leyes que se promulgaron durante el período revolucionario, algunas de las cuales iremos reseñando.
} 
primió esa vigilancia, que coartaba la libertad individual de desplazamiento ${ }^{13}$, y por ello la Constitución del 3 de septiembre de 1791 consagró como un derecho "la liberté à tout homme d'aller, de rester, de partir, sans pouvoir être arrêté ni détenu que selon les formes déterminées par la Constitution" ${ }^{14}$, con lo cual desaparecían de hecho los pasaportes interiores, pero la medida apenas se mantuvo medio año como veremos enseguida ${ }^{15}$.

Eso sí, para salir al extranjero siguió siendo obligatorio tras la Toma de la Bastilla, y muy en particular a raíz de ser sorprendidos Luis XVI y su familia en Varennes-en-Argonne el 21 de junio de 1791 tratando de huir. Los dirigentes vieron en los pasaportes un medio para controlar no sólo la emigración de la nobleza contrarrevolucionaria que buscaba acogerse a los ejércitos de las potencias europeas sino también la llegada de extranjeros de filiación monárquica ${ }^{16}$. El día 24 quedaba reconocida la libertad de circulación por el interior de Francia con la salvedad de inspeccionar a viajeros y mercaderes que se acercaran a menos de cinco leguas de la frontera, aunque sin mencionar la exigencia de pasaporte para cruzarla:

L'Assemblée Nationale décrète que la libre circulation des personnes et des choses dans l'intérieur du royaume et la marche des couriers et voyageurs ne pourront être arrêtées ni suspendues, mais devront être protégées par tous les corps administratifs et municipaux ainsi que par la Gendarmerie et les Gardes Nationales que, néanmoins dans les cinq lieues de la frontière, les corps administratifs et municipaux surveilleront exactement et feront vérifier la marche des couriers, voyageurs et les transports d'effets pour empêcher qu'il n'en passe à l'étranger jusqu'à ce qu'il en ait été autrement ordonné sans que, sous aucun prétexte, il puisse être apporté aucun obstacle à l'exécution des transactions ordinaires du commerce ${ }^{17}$.

Sólo cuatro días después otro decreto restringía la salida del país a extranjeros y comerciantes siempre y cuando unos y otros dispusieran de pasaporte, y fijaba los datos imprescindibles que debían figurar consignados:

Article premier. La libre sortie du royaume ne sera permise, jusqu'à ce qu'il en ait été autrement ordonné, qu'aux étrangers et aux négocians françois avec les précautions qui vont être indiquées pour les uns et pour les autres.

II. A l'égard des étrangers qui se trouvent à Paris, ceux qui sont nés ou domiciliés dans un état ou royaume qui entretient un ambassadeur ou ministre résidant en France, seront tenus de se munir d'un passe-port du ministre des Affaires Étrangè-

${ }^{13}$ G. NOIRIEL, "Surveiller les déplacements ou identifier les personnes?...", p. 78.

14 Título I, artículo 3.

${ }^{15}$ A. CHAUVEAU y H. FAUSTIN, Théorie du Code pénal, vol. II, Bruselas, 1837, p. 139.

${ }^{16}$ G. NOIRIEL, "Surveiller les déplacements ou identifier les personnes?...", p. 80.

${ }^{17}$ Collection générale des décrets rendus par l'Assemblée Nationale avec la mention des sanctions et acceptations données par le roi, vol. XV, París, 1791, p. 394. 
res accordé sur l'attestation écrite et signée des dits ambassadeurs ou résidens; ceux qui sont nés en d'autres pays, prendront également un passe-port du ministre des Affaires Étrangères qui sera accordé sur l'attestation de la municipalité de Paris constatant qu'ils sont connus pour étrangers et habitants de la capitale depuis tel temps.

III. Les étrangers habitant dans les autres villes de France se muniront de passeports signés de la municipalité du chef-lieu du district qu'ils habitent, ainsi qu'il vient d'être expliqué, sans avoir besoin de celui du ministre.

IV. Les négocians françois et couriers envoyés par les dits négocians qui voudront sortir du royaume seront également munis d'un passe-port de la municipalité du chef-lieu du district qu'habitent les dits négocians, et les officiers municipaux attesteront la vérité des fais et indications y contenus. [...]

VII. Tous les passe-ports contiendront le nombre des personnes à qui ils seront donnés, leur nom, leur âge, leur signalement, la paroisse habitée par ceux qui les auront obtenus, lesquels seront obligés de signer sur les registres des passe-ports et sur les passe-ports eux mêmes ${ }^{18}$.

El 14 de septiembre la Asamblea Nacional suprimió los pasaportes, tanto para viajar por Francia como al extranjero, promulgando un último decreto a favor de la libertad de circulación:

5. L'Assemblée Nationale décrète qu'il ne sera plus exigé aucune permission ou passeport dont l'usage avait été momentanément établi. [...] Conformément à la Constitution, il ne sera plus apporté aucun obstacle au droit de tout citoyen français de voyager librement dans le royaume et d'en sortir a volonté ${ }^{19}$.

Pese al proclamado principio de libertad, pronto fueron repuestos los salvoconductos interiores. Aprobó el primer decreto en este sentido la Asamblea Nacional el 1 de febrero de 1792 para promulgarlo el 28 de marzo; era el punto de partida de la serie de normas que iremos viendo y que alcanzarán su máximo rigor en época de Napoleón ${ }^{20}$ :

Art. $1^{\text {er. }}$. Toute personne qui voudra voyager dans le royaume sera tenu, jusqu'à ce qu'il en ait été autrement ordonné, de se munir d'un passe-port.

${ }^{18}$ Collection générale des décrets rendus..., vol. XV, pp. 449-450. El 3 de julio otro decreto extendió la posibilidad de salir del país a los franceses que trabajaran en embajadas extranjeras (vol. XVI, p. 13).

${ }^{19}$ Recueil général des lois, décrets, ordonnances, et cetera, depuis le mois de juin 1789 jusqu'au mois d'août 1830, vol. II, París, 1839, p. 424.

${ }^{20}$ G. NOIRIEL, "Surveiller les déplacements ou identifier les personnes?...”, p. 79. La mayor parte de las disposiciones que iremos mencionando están enumeradas en los siguientes listados, que nos han sido muy útiles para localizarlas en los códigos correspondientes: Recueil général des lois, décrets..., vol. III, París, 1839, p. 28; A. L. CARPENTIER y G. FRÈREJOUAN DU SAINT, Répertoire général alphabétique du Droit français, vol. XXIX, París, 1902, p. 898, y L. MÉROC, Faux passeports, faux permis..., p. 18. 
2. Les passe-ports seront donnés exclusivement par les officiers municipaux, et contiendront le nom des personnes auxquelles ils seront délivrés, leur âge, leur profession, leur signalement, le lieu de leur domicile et leur qualité de français ou d'étranger.

3. Les passe-ports seront donnés individuellement et seront signés par le maire ou autre officier municipal, par le secrétaire-greffier et par celui qui l'aura obtenu; dans le cas où ce dernier déclarera ne savoir signer, il en sera fait mention, et sur le passe-port et sur le registre de la municipalité.

4. Les passe-ports seront expédiés sur papier timbré, conformément au décret du 12 décembre 1790-18 février $1791^{21}$. Les voyageurs qui les obtiendront seront seulement assujetis aux frais du timbre.

5. Les français ou étrangers qui voudront sortir du royaume le déclareront à la municipalité du lieu de leur résidence, et il sera fait mention de leur déclaration dans le passe-port.

6. Les personnes qui entreront dans le royaume prendront, à la première municipalité frontière, un passe-port. [...]

9. Le voyageur qui n'en présentera pas, sera conduit devant les officiers municipaux pour y être interrogé et être mis en état d'arrestation, à moins qu'il n'ait pour répondant un citoyen domicilié.

10. Les officiers municipaux, suivant les réponses du voyageur arrêté ou les renseignements qu'ils en recevront, seront autorisés à le retenir en état d'arrestation ou à lui laisser continuer sa route; dans ce dernier cas, ils lui délivreront un passeport. [...]

15. Si le voyageur s'écarte de la route qui lui aura été tracée, il sera arrêté et conduit devant les officiers municipaux du lieu de l'arrestation. [...]

17. Tout français qui prendra un nom supposé dans un passe-port sera renvoyé à la police correctionnelle qui le condamnera à un emprisonnement qui ne pourra être moindre de trois mois ni excéder une année.

18. Il sera dressé pour tout le royaume une formule de passe-port qui sera annexée au présent décret ${ }^{22}$.

La crisis causada por las derrotas ante Austria y Prusia, así como la creciente tensión entre la Asamblea y el rey, determinaron que el 28 de julio se extremara el control a los franceses para viajar al extranjero:

Article I. Jusqu'à ce que l'Assemblée Nationale ait déclaré que la patrie n'est plus en danger, il ne pourra plus être délivré de passeport pour sortir du royaume à aucun citoyen français. Les passeports qui auroient été accordés jusqu'à ce jour pour sortir du royaume, et dont il n'auroit pas été fait usage, sont déclarés nuls ${ }^{23}$.

${ }^{21}$ Ahí se ordenaba que debían ser expedidos necesariamente en papel del Estado, entre otros muchos, "les registres des municipalités pour tout ce qui concernera leurs affaires et sera étranger aux fonctions publiques qui leur sont déléguées par les lois", así como "les expéditions, extraits, copies certifiées, de tous les registres mentionnés" (Recueil général des lois, décrets..., vol. I, París, 1839, pp. 431-432).

${ }^{22}$ Recueil général des lois, décrets..., vol. III, pp. 28-29.

${ }^{23}$ Collection générale des décrets rendus..., vol. XXIII, París, 1792, p. 136. 
El 7 de diciembre, una vez proclamada la República, establecida la Convención, iniciado el proceso contra Luis XVI, y tras algunas victorias militares sobre la Primera Coalición, se flexibilizó la norma permitiendo obtener pasaporte a cualesquiera franceses "qui seroient dans la nécessité de sortir du territoire de la République pour leurs intérêts ou pour leurs affaires”, previa autorización de las autoridades provinciales y municipales "s'ils jugent les causes légitimes et suffisamment vérifiées" 24 .

En el otoño de 1795, durante los últimos días de la Convención, y recién aprobada la Constitución del Año III que daría paso al Directorio apenas un mes después, se publicó el 2 de octubre un Décret sur la police intérieure des communes, cuyo título III está dedicado a los pasaportes:

Article $1^{\mathrm{er}}$. Jusqu'à ce qu'autrement il en ait été ordonné, nul individu ne pourra quitter le territoire de son canton ${ }^{25} \mathrm{ni}$ voyager sans être muni et porteur d'un passeport signé par les officiers municipaux de la commune ou administration municipale du canton.

2. Chaque municipalité ou administration municipale du canton tiendra un registre des passe-ports qu'elle délivrera.

3. Tout passe-port contiendra le signalement de l'individu, sa signature ou sa déclaration qu'il ne sait signer, rélérera le numéro de son inscription au tableau de la commune, et sera renouvelé au moins une fois par an. A cet effet l'administration de département fera passer à chaque municipalité ou administration municipale un modèle de passe-port ${ }^{26}$.

El Directorio (1795-1799) ratificó el 4 de marzo de 1796 la competencia municipal sobre expedición de pasaportes ${ }^{27}$, y tres días más tarde exigió nuevos requisitos de identificación personal:

Article $1^{\text {er }}$. Les membres des administrations et autorités chargées par les lois de la délivrance des passeports n'en donneront qu'aux citoyens qu'ils connaîtront personnellement. S'ils ne les connaissent pas, ils ne les délivreront que sur l'attestation de deux citoyens connus, dont les noms seront désignés dans le passeport qu'ils seront tenus de signer; et s'ils ne savent pas signer, il en sera fait mention.

2. Les fonctionnaires publics qui contreviendraient à l'article précédent seront destitués de leurs fonctions et punis, par voie de police correctionnelle, d'un emprisonnement qui ne pourra être moindre de trois mois ni excéder une année.

3. Les témoins qui attesteraient un nom supposé dans un passeport; les logeurs, aubergistes ou maitres de maisons garnies qui inscriraient sur leurs registres des

${ }^{24}$ Collection générale des décrets rendus par la Convention Nationale avec la mention de la date de l'apposition du sceau, vol. XXXII, París, 1792, p. 27.

${ }^{25}$ El cantón es una división administrativa creada en 1789 que agrupa a varios municipios, generalmente menos de diez.

${ }^{26}$ Recueil général des lois, décrets..., vol. VI, París, 1839, p. 196.

${ }^{27}$ Recueil général des lois, décrets..., vol. VI, p. 420. 
noms qu'ils savent n'être pas ceux des individus logés chez eux; les citoyens qui certifieraient ces déclarations par devant les autorités constituées, seront punis des mêmes peines ${ }^{28}$.

El 19 de octubre de 1797 el Directorio establece su propia ley sobre pasaportes, cuyas principales novedades consisten en hacer constar el lugar de destino, y en someterlos al control de comisarios nombrados por el gobierno:

Article $1^{\text {er }}$. Les passeports qui, conformément aux dispositions des lois, doivent être délivrés aux citoyens français ou étrangers, désigneront a l'avenir les lieux ou les voyageurs doivent se rendre. Ils seront visés par le commissaire du Directoire exécutif près de l'administration chargée de la délivrance des passeports.

2. Dix jours après la promulgation de la présente, tous passeports d'une date antérieure à cette promulgation demeurent annulés. Pendant ce délai, les citoyens absens de leur domicile prendront, auprès de l'administration municipale du canton où ils se trouvent momentanément, un nouveau passeport qui ne pourra leur être délivré que sur la réclamation de deux citoyens domiciliés connus dans le canton, dont la déclaration signée sera mentionnée au passeport ainsi que sur les registres de l'administration. Une copie du passeport ainsi renouvelé sera adressée à l'administration municipale du canton où se trouve le domicile du citoyen qui l'aura obtenu.

3. Les étrangers non domiciliés qui voyagent ou résident actuellement dans l'intérieur de la République, seront également obligés de se présenter auprès de l'administration centrale du département où ils se trouvent pour y faire vérifies leurs passeports et ajouter la désignation des lieux où ils désirent voyager et résider momentanément. Les commissaires du Directoire près ces administrations, adresseront copie de ces passeports ainsi renouvelés au ministre des Relations Extérieures et à celui de la Police Générale ${ }^{29}$.

El 11 de octubre de 1799 la última disposición del Directorio a este respecto, hizo obligatorio el pasaporte para desplazarse a las colonias ${ }^{30}$.

\subsection{Los pasaportes del Consulado (1799-1804).}

No hubo otra novedad que la orden de 13 de agosto de 1800 que dejaba sin vigor cualquier pasaporte extranjero, mientras Francia sufría el acoso de la Segunda Coalición en el Rin, Suiza y el norte de Italia, y las tropas imperiales eran expulsadas de Egipto:

Article $\mathrm{I}^{\mathrm{er}}$. Les passe-ports ou sauf-conduits accordés par les ministres et autres agens diplomatiques des puissances alliées ou neutres, soit à des individus qui ne

\footnotetext{
${ }^{28}$ Recueil général des lois, décrets..., vol. VI, p. 421.

${ }^{29}$ Recueil général des lois, décrets..., vol. VII, París, 1839, p. 220.

${ }^{30}$ Recueil général des lois, décrets..., vol. VIII, París, 1839, p. 309.
} 
sont pas de leur nation soit à des français naturalisés chez ces puissances, depuis le 14 juillet 1789, ne seront point admis en France.

II. L'entrée du territoire de la République est interdite aux personnes désignées dans l'article précédant sous peine d'être traitées comme gens sans aveu ou comme émigrés.

III. Tout étranger actuellement en France en vertu de passe-port à lui délivré par un ministre ou agent d'une puissance alliée ou neutre, et qui se trouve dans le cas de l'article $I^{\mathrm{er}}$ du présent arrêté, est tenu de faire constater, d'ici au 15 fructidor [2 de septiembre], par un certificat du ministre ou agent de sa nation résidant en France, qu'il est de la nation au nom de laquelle le passe-port lui a été délivré.

IV. Tout étranger qui se trouve dans le cas prévu par l'article $\mathrm{I}^{\text {er }}$ et qui n'aura pas satisfait aux dispositions ci-dessus, sera arrêté et conduit hors du territoire de la République.

V. Tout individu né français actuellement en France en vertu d'un passe-port étranger, sera tenu, pour pouvoir y continuer son séjour, de se pourvoir, dans le délai de trois jours pour Paris et de deux décades ${ }^{31}$ pour les départements, de la permission expresse du ministre de la Police Générale sous peine d'être traité comme prévenu d'émigration ${ }^{32}$.

\subsection{Los pasaportes imperiales (1804-1814).}

Como quedó dicho al principio, fue la época de más leyes sobre pasaportes en Francia.

En 1806 Joseph Balthazar Bonet de Treyches (1757-1828), uno de los diputados que habían participado en el Juramento del Juego de Pelota el 20 de junio de 1789, director bajo Napoleón de diversas instituciones artísticas, imprimió "pour être mis uniquement sous les yeux de l'autorité publique" el opúsculo Vues nouvelles sur les passe-ports, un informe que le había sido encargado a principios de 1799 "par ordre du Corps Législatif".

La propuesta central de Bonet de Treyches consistía en crear un modelo único de pasaporte que con certeza pudiera ser reconocido por las autoridades:

Nous proposons de substituer aux passe-ports actuels, vicieux sous tous les rapports, de nouveaux passe-ports, uniformes, identiques, dont la vérification sera prompte et certaine, et la contrefaçon impossible ${ }^{33}$.

${ }^{31}$ Estas décadas eran los períodos de diez días que sustituyeron a las semanas en el calendario republicano francés (A. GIRY, Manuel de Diplomatique, París, 1894, p. 171, y J. M. DE FRANCISCO OLMOS, Manual de cronología. La datación documental histórica en España, Madrid, 2009, p. 342).

${ }^{32}$ Bulletin des lois de la République, $3^{\text {a }}$ serie, núm. 37, París, 1800, pp. 3-4.

33 J. B. BONET DE TREYCHES, Vues nouvelles sur les passe-ports, p. 1. En la página siguiente denuncia que "environ 55.000 autorités municipales ou administratives sont investies dans l'empire français de la faculté de délivrer des passe-ports. Chacune d'elles a ses formes, son mo- 
Para conseguir esa uniformidad propone que los imprima en París una sola fábrica controlada por el gobierno “comme le sont aujourd'hui les billets de loterie et les billets de banque" 34 .

Desde el punto de vista de la Diplomática interesa en particular la segunda parte de la obra, dedicada fundamentalmente a los aspectos técnicos que deben tenerse en cuenta a la hora del diseño ${ }^{35}$. Comienza refiriéndose a la "ordonnance générale" del pasaporte, que habría de ir rodeado por una orla sencilla; como se hacía también en España a partir del Trienio Liberal ${ }^{36}$.

La forme doit en être régulière, et présenter pour encadrement une bordure légère, dont les parties, quoique variées, offrent à l'œil un ensemble harmonieux et un tout indivisible. [...] Enfin, la composition et les détails doivent être tels qu'il en résulte un passe-port facile à reconnaître, qu'on ne puisse imiter.

Aconseja luego confeccionarlos mediante talonarios que permitan a la autoridad otorgante conservar una matriz de cada pasaporte entregado, lo que en términos de génesis documental se conoce como la minuta y el mundum:

La feuille destinée à devenir un passe-port, tenant à un registre relié ou cartonné, sera composée de deux parties. La première, qui se détachera de l'autre par une coupure ondulée et latérale, sera le passe-port que l'on délivrera au certifié. La seconde en sera le talon, et restera inhérente au registre. L'une et l'autre contiendront les mêmes écritures, détails, numéros, signatures et renseignemens. Ainsi, le talon sera minute et le passe-port expédition.

La textura del papel tenderá también a obstaculizar las falsificaciones, y alerta sobre la escasa garantía de las marcas de agua:

Les qualités les plus essentielles à donner au papier sont la finesse, l'élasticité, le nerf et, surtout, la minceur, pour éviter le grattage, et parce que le papier fort est sujet à se couper. Sa pâte doit contenir des substances telles que la moindre tentative à l'aide d'acides pour en faire disparaître l'écriture, soit révélée sur-le-champ, et devienne sensible aux yeux les moins clairvoyans. Son étoffe doit porter des signes frappans et inaltérables. Les filigranes seuls ne suffiraient pas: il existe plusieurs moyens de les imiter.

dèle et sa rédaction particulière. Le seul objet qui leur soit commun est le papier timbré". Había entonces múltiples formatos, como pudimos comprobar trabajando en otro artículo sobre el Reino de las Dos Sicilias: J. C. GALENDE DÍAZ y N. ÁVILA SEOANE, "De Nápoles a Toledo, un reiterado periplo...", en prensa.

${ }^{34} \mathrm{~J}$. B. BONET DE TREYCHES, Vues nouvelles sur les passe-ports, p. 9.

${ }^{35} \mathrm{~J}$. B. BONET DE TREYCHES, Vues nouvelles sur les passe-ports, pp. 11-23.

36 J. C. GALENDE DÍAZ y M. GARCÍA RUIPÉREZ, "Los pasaportes, pases y otros documentos de control...", p. 177. 
Pasando al detalle de los talonarios recomienda otras medidas de seguridad: la línea de corte entre matriz y pasaporte dispondrá de marca de agua y de un texto superpuesto longitudinalmente, de letra compleja e impreso con tinta roja (este recurso ya había sido empleado en las cartas partidas, típicas del período pleno y bajomedieval ${ }^{37}$ ), el sello seco y las firmas del funcionario y del viajero:

Les talons que l'on propose ici sont combinés de manière à bannir jusqu'à l'ombre de l'inquiétude.

La souche à gauche occupera précisément la moitié de la feuille dans sa longueur parce que cette souche doit contenir l'analyse exacte du passe-port, c'est-àdire: le nom du département et de la commune, la date, les nom, prénoms, âge, lieu de naissance, de départ, de passage et de destination ultérieure, enfin, le signalement pittoresque de l'individu. L'autre moitié de la feuille à droite sera le passeport même.

Au milieu de la feuille, prise en longueur, la bande du passe-port qui le joint à la souche sera marquée par des filigranes bien prononcés, qui formeront dans l'étoffe du papier un premier talon transparent et ineffaçable.

Au recto, des lettres bien dessinées et des traits confusément entrelacés, présenteront un deuxième talon, qui doit être imprimé d'une couleur particulière (rouge) et différente de celle qu'on emploiera (noire) pour le texte de la souche et du passeport.

$\mathrm{Au}$ centre de ce talon typographique, ou réserve en blanc la mouche circulaire sur laquelle doit être frappé le timbre sec qui donne un troisième talon.

$\mathrm{Au}$ verso du talon, sur les parties correspondantes au talon imprimé, devront être posées en longueur et hors de la mouche, deux signatures: l'une, celle de l'officier public; l'autre, celle du demandeur du passe-port. Ces signatures, dont les formes et la position varient sans cesse, tandis que le talon typographique est constant, offrent un quatrième talon.

Enfin la coupe onduleuse qui sépare le passe-port de la souche procure un cinquième talon.

Tipográficamente, sugiere emplear diversos moldes y que sean diferentes a los tipos habituales, llegando a proponer errores de impresión simulados:

L'ensemble de la composition doit présenter des caractères romains et italiques $^{38}$, de la ronde et de l'écriture anglaise, en grandes et petites lettres. Ces caractères auront des différences sensibles de formes et de proportions avec toutes les matrices connues et vulgairement employées dans les diverses imprimeries. Leurs formes doivent être, de la beauté, la plus parfaite, et réunir les contours les plus purs.

Il est cependant avantageux d'y établir exprès quelques négligences ou signes particuliers destinés à la découverte des faux passe-ports. C'est un des meilleurs moyens à la faveur desquels on peut porter obstacle à toute imitation coupable. En

${ }^{37}$ J. C. GALENDE DÍAZ, "Un sistema de validación documental: de la quirografía a las cartas partidas", Espacio, tiempo y forma. Serie III: Historia Medieval, 9 (1996), pp. 362-363.

${ }^{38}$ Es decir: letras rectas e inclinadas. 
effet, les imitateurs, placés loin du secret de ces imperceptibles et volontaires erreurs, qui consistent en cassures, linéamens, et autres prétendus accidens, ne pourront être assez clairvoyans pour les reproduire, et tomberont dès-lors dans le piège qu'on leur aura ainsi préparé.

La combinación de grafías redondas (écriture ronde française, utilizada sobre todo en los siglos XVIII y XIX, que se caracteriza por unas letras abultadas y rectas) e inglesas (difundidas en Francia desde principios del Ochocientos, inclinadas hacia la derecha) puede apreciarse claramente en el ejemplar de Escalona:

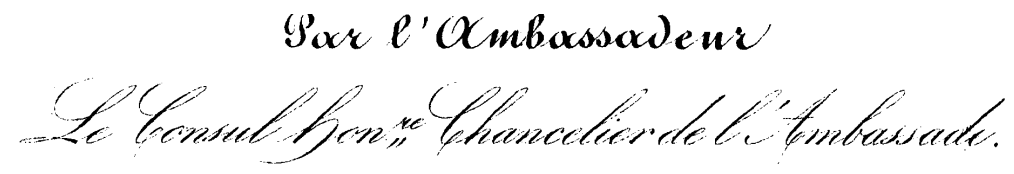

Recomienda igualmente superponer más de un procedimiento de grabado, extendiéndose aquí en los aspectos técnicos, y usar tintas de varios colores: el texto principal, en negro; la escritura cortada al separar la matriz, en rojo, y la impronta, en azul:

Pour l'impression on en emploie de trois couleurs différentes: $1^{\circ}$ une encre d'un noir luisant et velouté pour le texte; $2^{\circ}$ pour le talon une encre d'un rouge vif et semblable à celle dont furent imprimées les promesses de mandats; $3^{\circ}$ pour la griffe identique ou de rencontre et son revers une encre d'un bleu pur, semblable à celle qu'on a également employée dans les mêmes promesses ${ }^{39}$.

Otro de los apartados del pasaporte que requería especial cuidado era una descripción fisonómica que garantizara la identificación personal del viajero, algo que no sería fiable hasta la incorporación de la fotografía durante la segunda mitad del siglo XIX $^{40}$.

Tout le monde, à cet égard, est convaincu de deux vérités: $1^{\circ}$ que les signalements actuels sont d'une défectuosité choquante; $2^{\circ}$ qu'il est indispensable de les rendre, pour ainsi dire, pittoresques et frappans de ressemblance. Le signalement est le portrait écrit de l'individu signalé. [...]

Nous avons combiné un mode de signalement qui ne permettra plus de se méprendre sur l'individu signalé. La physionomie, le profil, la corpulence, les marques particulières, les cicatrices, le costume, l'habitude du corps, ce qu'on appelle l'air, c'est-à-dire, le caractère le plus distinctif de l'extérieur, seront définis, à l'aide de notre méthode, de manière à prévenir toute erreur.

${ }^{39}$ Se da este nombre al papel moneda emitido por el Directorio en 1796 con el respaldo de lo que quedaba de los bienes incautados durante la desamortización. Se utilizó tinta roja para imprimir los mandatos de 100 francos, y de un azul grisáceo para los de 500.

${ }^{40}$ M. FRIZOT, S. JULY, C. PHÉLINE y J. SAGNE, Identités. De Disderi au photomaton, París, 1985, y G. NOIRIEL, "Surveiller les déplacements ou identifier les personnes?...”, pp. 86100 . 
Y para que las autoridades puedan reconocer fácilmente a los tenidos por indeseables o de mala ralea, propone encriptar marcas secretas:

Autant il est dû de protection aux honnêtes citoyens, autant il est essentiel de tenir sous une surveillance sévère les vagabonds, les aventuriers et les mauvais sujets. La circulation des premiers es souvent profitable, celle des derniers est toujours funeste. Pour distinguer les uns des autres nous proposons de placer sur les passe-ports des signes récognitifs secrets qui serviront seulement aux autorités auxquelles seront présentés les passe-ports.

Termina el informe recomendando cuidar escrupulosamente todos los trámites, desde la fabricación del papel hasta la entrega definitiva, proponiendo como prueba infalible de autenticidad cotejar al trasluz el sospechoso con un original ("la vérification de deux papiers minces et diaphanes sera facile et sûre par la superposition. [...] Cette confrontation se fera en plaçant deux passe-ports, l'un sur l'autre, de manière que les clairs et les sombres du papier, surtout les caractères d'impression, se couvrent au point de se confondre et que, regardés au jour ou à la lumière, ils ne présentent plus à l'œil qu'une seul et même image"), y fijando un protocolo de control al distribuir los pasaportes vírgenes a las oficinas de despacho $^{41}$. Centrado en los aspectos de seguridad, Bonet de Treyches no entra en los de índole formularia o de redacción.

Hay por último un compendio general coronado con esta entusiasta laudatoria del emperador ${ }^{42}$ :

Napoléon-le-Grand a soumis au principe de l'uniformité les lois, les administrations, les mesures et les droits de tous. Notre proposition a le même principe pour base. Ses avantages sont évidens. Puisse-t-elle fixer les regards du génie qui veille sur l'empire, obtenir son suffrage et être admise au nombre de ses travaux et de ses bienfaits!

El 18 de septiembre de 1807 vuelve a regularse la expedición de pasaportes recogiendo ahora buena parte de las propuestas de Bonet de Treyches sobre uniformidad, fabricación centralizada y empleo de talonarios y papel especial, al tiempo que fija las tasas de emisión:

Article $1^{\text {er }}$. Les passeports accordés pour voyager dans l'intérieur de l'empire ou pour en sortir, tant aux français qu'aux étrangers, ne pourront être délivrés que sur un papier fabriqué spécialement à cet effet et sur un modèle uniforme.

2. La feuille disposée pour le passeport se composera de deux parties. La première, qui se détachera de la seconde par une coupure ondulée, sera remise au porteur et constituera le passeport. La seconde partie, par forme de souche ou talon,

${ }^{41}$ J. B. BONET DE TREYCHES, Vues nouvelles sur les passe-ports, pp. 24-28.

${ }^{42}$ J. B. BONET DE TREYCHES, Vues nouvelles sur les passe-ports, pp. 29-35. 
sera la minute du passeport délivré, contiendra les mêmes désignations que le passeport et restera entre les mains de l'autorité qui aura délivré le passeport.

3. Le ministre de la Police Générale de l'empire est spécialement chargé de faire fabriquer et imprimer les exemplaires desdits passeports et les distribuera à toutes les autorités compétentes, qui s'en chargeront sur récépissés.

4. Il ne pourra être payé pour chaque passeport, pour tous frais y compris ceux de fabrication et de timbre, que la somme de deux francs.

5. Les visa ordonnés par les lois et réglemens sur les passeports accordés seront donnés gratuitement, soit aux frontières soit dans l'intérieur.

6. Au 31 décembre tous ceux qui, étant en France, seront porteurs de passeports délivrés sous une formule autre que celle adoptée par le présent, seront tenus de se pourvoir de passeports délivrés dans la nouvelle forme.

7. Les contrevenans à ces dispositions seront soumis aux peines prononcées contre les individus qui voyagent sans passeport par les lois des 28 mars 1792 et 10 vendémiaire an 4 [2 de octubre de 1795$]^{43}$.

El 11 de julio de 1810 culmina la reglamentación imperial sobre pasaportes fijando cómo ha de remitirse a la Hacienda pública el producto de las tasas, y, lo que resulta más interesante para el objetivo de este artículo, estableciendo el plazo de validez en un año y preceptuando que el importe vaya impreso:

Article 4. L'administration de l'enregistrement adressera au directeur de chaque département les registres de passe-ports nécessaires au service sur les ordres de notre ministre de la Police Générale.

5. Le directeur de chaque département prendra les ordres du préfet pour l'envoi des registres de passe-ports aux receveurs ou percepteurs des contributions de chaque commune.

6. La recette du prix des passe-ports sera versée chaque mois à la caisse du receveur des contributions du chef-lieu d'arrondissement avec indication du nombre des passe-ports qui auront été délivrés dans le mois. Il en sera fait un article particulier de recette dans les comptes. Chaque mois, les receveurs d'arrondissement adresseront au directeur de l'enregistrement le bordereau indicatif du nombre des passe-ports et de la recette.

7. La régie de l'enregistrement pourra faire vérifier, par ses préposés, l'état des registres de passe-ports toutes les fois qu'elle le jugera utile.

8. Les passe-ports ne seront valables que pour un an à dater du jour de leur délivrance.

9. Le prix des passe-ports est fixé, savoir: pour les passe-ports à l'intérieur de l'empire à deux francs; pour les passe-ports à l'étranger à dix francs. Dans cette fixation sont compris les frais de papier et de timbre et tous frais d'expédition. Les prix ci-dessus fixés seront imprimés sur les passe-ports ${ }^{44}$.

\footnotetext{
${ }^{43}$ Recueil général des lois, décrets..., vol. XI, París, 1839, pp. 213-214.

${ }^{44}$ Recueil général des lois, décrets..., vol. XII, París, 1839, p. 65.
} 


\subsection{Los pasaportes de la Restauración y la Monarquía de Julio (1814-} 1848).

El 20 de abril de 1814, sólo once días después de que Napoleón abdicara en Fontainebleau y mientras preparaba su exilio a Elba, Carlos Felipe de Borbón, hermano del recién entronizado Luis XVIII (1814-1824) y lugarteniente del reino, confirmó la vigencia de las disposiciones sobre pasaportes promulgadas durante la Revolución y el Imperio:

Au château des Tuileries, le 20 avril 1814, nous Charles-Philippe de France, fils de France, monsieur, frère du roi, lieutenant général du royaume, sur le rapport du commissaire au département de la Police Générale, le Conseil d'État provisoire entendu, ordonnons ce qui suit:

Article $I^{\mathrm{er}}$. Les lois et réglements sur les passe-ports, tant à l'étranger qu'à l'intérieur, sont maintenus et continueront à être exécutés comme par le passé.

2. L'administration de l'enregistrement et des domaines fera confectionner les formules d'après les modèles annexés à la minute de la présente ordonnance, dont le commissaire provisoire au département de la Police Générale est chargé de l'exécution ${ }^{45}$.

El 21 de diciembre Luis XVIII confirmaba entre otras tasas de expedición, las de los pasaportes ${ }^{46}$.

Repuesto en el trono tras los Cien Días del regreso de Napoleón, el rey dictó un reglamento sobre pasaportes en 1816, que fue analizado por Gérard Noiriel ${ }^{47}$. De su estudio se deduce que todo francés mayor de quince años que quisiera salir de su departamento de residencia, debía disponer de la siguiente documentación

${ }^{45}$ Bulletin des lois du royaume de France, $5^{\mathrm{a}}$ serie, núm. 12, París, 1814, p. 100.

${ }^{46}$ Bulletin des lois du royaume de France, $5^{\mathrm{a}}$ serie, núm. 65, París, 1814, p. 580. Volvería a ratificarlas el 28 de abril de 1816 ( $7^{\mathrm{a}}$ serie, núm. 81, p. 510) y el 15 de mayo de 1818 ( $7^{\mathrm{a}}$ serie, núm. 211, p. 339).

${ }^{47}$ Lo consultó en los Archives Départamentales de la Vendée ("Surveiller les déplacements ou identifier les personnes?...”, p. 79). No hay referencias a este reglamento en el Bulletin des lois du royaume de France del año 1816 (según la Table décennale du Bulletin des lois depuis le $1^{e r}$ avril 1814 jusqu'au 31 décembre 1823, publicada en París en 1826 por Éléonor Lonchampt, sólo se emplea la palabra pasaporte durante esos años en la Loi sur les finances del 28 de abril de 1816 acabada de citar y cuyo artículo 77 mantiene diversas tasas de expedición) ni en Les lois administratives et municipales de la France ou Manuel théorique et pratique des préfets, des souspréfets et des maires, des conseils de préfecture, de département, d'arronsissement et municipaux, contenant, par ordre alphabétique, les dispositions textuelles ou analytiques des lois, des décrets, des ordonnances du roi, des circulaires, instructions et décisions ministérielles actuellement en vigueur, depuis 1789 jusqu'à 1823, vol. IV, París, 1823, pp. 6-15, donde se recoge casi toda la legislación descrita anteriormente y algunas otras disposiciones sobre pasaportes para pobres adoptadas en 1819. Sí se refiere a él M. BORDIGONI, “"Vos papiers, s'il vous plaît»: invention des identités de papiers...”, pp. 374-375, aunque se limita a reproducir de manera muy resumida lo expuesto por Noiriel. 
en regla: una hoja de ruta para los militares, o bien un pasaporte "à l'étranger", "à l'interieur" o "pour indigent"; los extranjeros tendrían que depositar en la frontera el pasaporte de su país de origen, a cambio de un "passe" para moverse por Francia. La validez de estos salvoconductos solía ser de un año y se expedían mediante talonarios como los descritos por Bonet de Treyches, confeccionados en "papier uniforme à filigrane" 48 .

Tras la Revolución de Julio, Luis Felipe (1830-1848) fijó el 25 de octubre de 1833 las competencias de los cónsules para expedir pasaportes a los compatriotas residentes en el exterior, y lo mismo a los extranjeros que quisieran viajar a Francia, o bien, visarles los emitidos por sus propias autoridades:

Article $1^{\text {er }}$. Nos consuls sont autorisés à délivrer des passeports aux français qui se présenteront pour en obtenir, après s'être assurés de leur qualité et identité. Ils les délivreront dans les formes prescrites par les lois, ordonnances et règlements en vigueur en France: ils y énonceront le nombre des personnes auxquelles ils seront remis, I ${ }^{\text {eurs }}$ noms, âge, signalement, et feront signer celles qui le pourront, tant sur le registre constatant la délivrance que sur le passe-port.

2. Tous français voyageant en pays étranger devra, à son arrivée dans les lieux où résident nos consuls, présenter son passe-port à leur visa a fin de s'assurer leur protection. Le visa ne sera accordé qu'autant que le passe-port aura été délivré dans les formes déterminées par les lois, ordonnances et usages du royaume. [...]

4. Nos consuls sont autorisés, dans tous les cas où les lois et usages du pays dans lequel ils sont établis n'y font pas obstacle, à délivrer des passe-ports pour France aux étrangers qui leur en demanderont. Ils se conformeront, à cet égard, aux instructions qu'ils recevront de notre ministre secrétaire d'état des Affaires Étrangères.

5. Ils viseront, en se conformant également aux instructions de notre ministre secrétaire d'état des Affaires Étrangères, les passe-ports délivrés pour la France à des sujets étrangers par des autorités étrangères, lorsque ces passe-ports leur paraîtront expédiés dans les formes régulières ${ }^{49}$.

Desde esta época empezarán a manifestarse diversos problemas al respecto, como la inseguridad, ya señalada, para identificar al portador, o el descuidado control de los ayuntamientos, agravado por la renuencia de muchos forasteros a personarse ante las autoridades. Además, la expansión del liberalismo (que proponía la mínima intervención del Estado en la vida privada), el desarrollo del ferrocarril (las compañías eran reacias a la exigencia del pasaporte a sus clientes) y la revolución industrial (que provocó una rápida y masiva emigración del campo a las fábricas) influyeron en su paulatino abandono. Aunque nunca se abolió for-

\footnotetext{
${ }^{48}$ G. NOIRIEL, "Surveiller les déplacements ou identifier les personnes?...”, pp. 79 y 89.

${ }^{49}$ Bulletin des lois du royaume de France, $9^{a}$ serie, parte II, núm. 266, París, 1833, p. 464.
} 
malmente, su uso en el interior de Francia ${ }^{50}$ prácticamente había desaparecido al proclamarse la III República en 1870. Distinto era el paso fronterizo, pues los tratados internacionales generalmente no admitían a extranjeros sin un pasaporte en regla de su país de origen ${ }^{51}$.

En cuanto a la legislación, el Répertoire général alphabétique du Droit français no recoge ninguna nueva norma hasta el del 9 de diciembre de $1881^{52}$, en tiempos ya de la III República y casi treinta años después de la expedición del pasaporte conservado en el Archivo Histórico Municipal de Escalona.

Por haber sido objeto de otro estudio reciente, obviamos aquí la normativa española respecto a pasaportes, a la que también estuvieron sometidos lógicamente los poseedores de los dos de este trabajo ${ }^{53}$.

\section{ESTUDIOS DIPLOMÁTICO Y PALEOGRÁFICO.}

En cuanto a la configuración, sí apuntaremos someramente, a título comparativo, que en la España de la primera mitad del siglo XIX los pasaportes consisten generalmente en formularios impresos, de tamaño folio, con espacios para rellenar a mano los datos del portador. A partir del Trienio Liberal suelen ir orlados, y el texto se distribuye así: un encabezamiento en la parte superior, donde aparece el escudo nacional; el bloque principal, en el centro; los elementos validativos, debajo, y en una columna, habilitada casi siempre a la izquierda, el número de registro, las marcas identificativas y la firma del titular ${ }^{54}$. Se prescinde del sistema de talonarios.

Respecto a su estructura diplomática, lo habitual en España es que la dispositio consista en la propia concesión del pasaporte a su titular, referenciado en la directio. Sin embargo, como veremos enseguida, los modelos franceses están diri-

${ }^{50}$ A. L. CARPENTIER y G. FRÈREJOUAN DU SAINT, Répertoire général alphabétique du Droit français, vol. XXIX, p. 899.

${ }^{51}$ L. MÉROC, Faux passeports, faux permis..., pp. 37-41, y G. NOIRIEL, "Surveiller les déplacements ou identifier les personnes?...”, pp. 86-100.

52 A. L. CARPENTIER y G. FRÈREJOUAN DU SAINT, Répertoire général alphabétique du Droit français, vol. XXIX, p. 898. Sobre este período puede consultarse M. D'HARTOY, Histoire des passeports français..., pp. 69-71.

${ }^{53}$ Véanse J. C. GALENDE DÍAZ y M. GARCÍA RUIPÉREZ, "Los pasaportes en España durante el Trienio Liberal...", pp. 222-228, y "Los pasaportes, pases y otros documentos de control...”, pp. 115-144, y 303 (2004), pp. 169-173, y J. C. GALENDE DÍAZ, Fuentes onomásticas: el pasaporte como documento inspector, pp. 32-45.

54 J. C. GALENDE DÍAZ y M. GARCÍA RUIPÉREZ, "Los pasaportes, pases y otros documentos de control...", pp. 177-179, y J. C. GALENDE DÍAZ, "Fuentes onomásticas: el pasaporte como documento...", pp. 46-54. 
gidos a las autoridades, tanto propias como extranjeras, para que faciliten el tránsito al viajero ${ }^{55}$.

\subsection{Pasaporte del reinado de Luis Felipe (1836).}

El ejemplar conservado en el Archivo Municipal de Toledo mide 420 por 330 milímetros y está desgajado de un talonario, conforme al método propuesto por Bonet de Treyches. Una vez consumido, a finales de enero de 1837, el espacio para ir visando, hubo que añadirle una segunda hoja que se cosió a la primera mediante un par de puntadas.

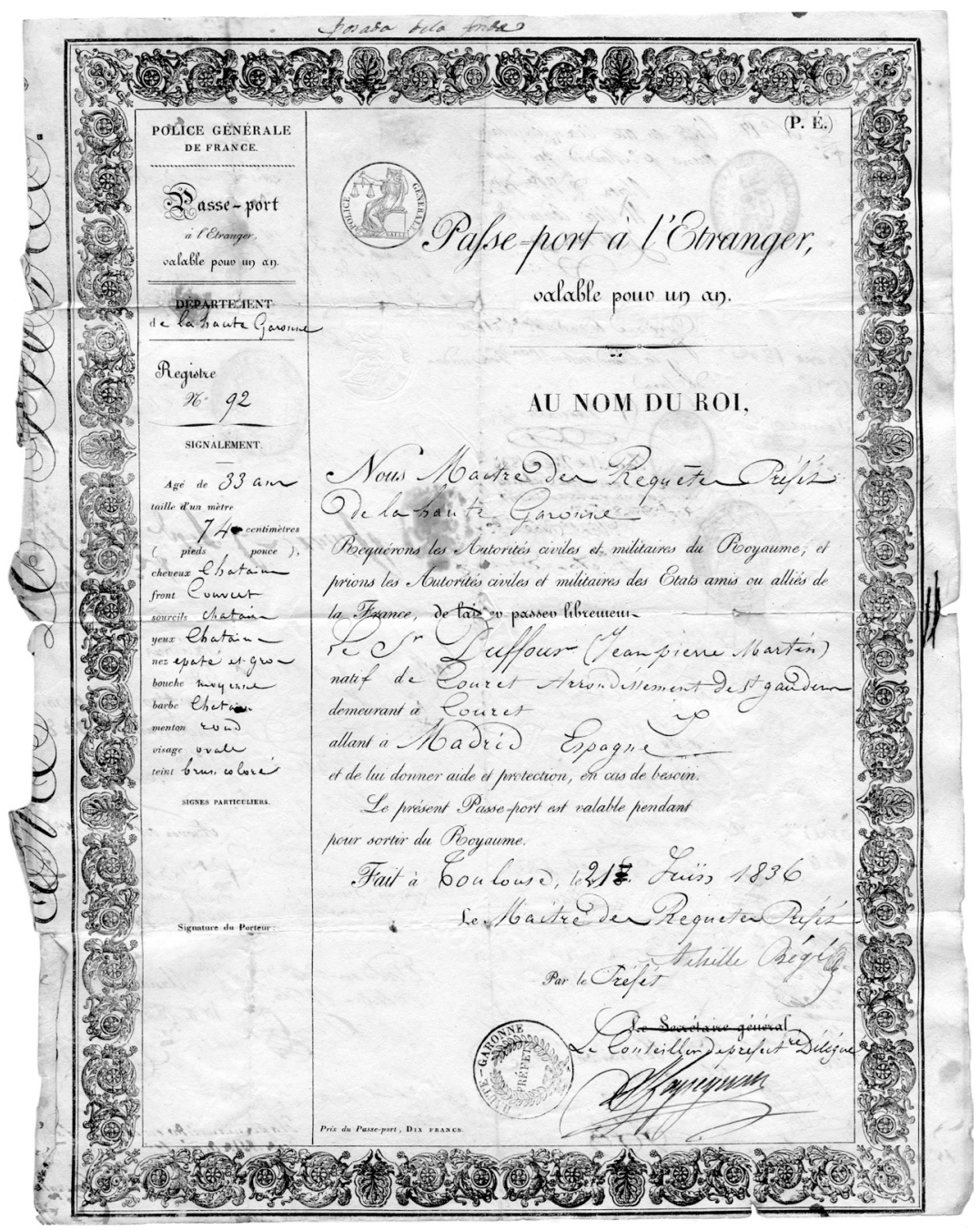

${ }^{55}$ El modelo francés es muy similar al de buena parte de los pasaportes del Reino de las dos Sicilias (J. C. GALENDE DÍAZ y N. ÁVILA SEOANE, "De Nápoles a Toledo, un reiterado periplo...", en prensa). 
El formulario preimpreso, a diferencia de lo que había sugerido Bonet, va todo en tinta negra, y, del texto que iba a caballete sobre la línea de corte, puede leerse la parte inferior de las palabras Royaume de France en una escritura sumamente enrevesada como un obstáculo más contra la posible falsificación. Tiene también una marca de agua en la que puede leerse el texto passe-port à l'étranger, distribuido en dos renglones, entre los cuales hay un busto de perfil del monarca con la leyenda, toda en mayúsculas, Louis Philippe I roi des français. Además de la orla (otro elemento protector que recorre todo el contorno), una línea vertical margina la acostumbrada columna a la izquierda, donde van las señas personales del titular.

Tal y como recomendaba Bonet de Treyches, se combinan múltiples modelos de letra impresa:

- Abunda sobre todo la inglesa, que ocupa casi todo el texto tipográfico del cuerpo principal del pasaporte, así como la expresión à l'étranger de la columna izquierda, donde también se echa de ver que la $N$ que abrevia Numéro difiere mucho de la del Nous de la intitulación, aun siendo ambas inglesas.

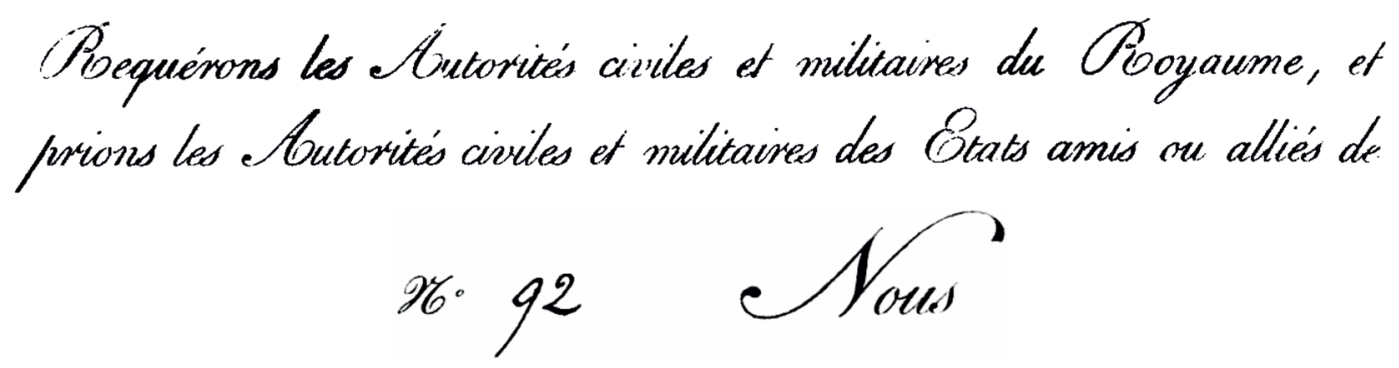

- En cambio la escritura redonda, que también citaba expresamente Bonet de Treyches, ocupa escasas palabras: registre, le, le sécrétaire général, de laisser passer librement, y dos veces valable pour un an.

\section{solable pouv un an.}

- Una humanística con caracteres capitales romanos da soporte a los encabezamientos de la columna izquierda, así como a la abreviatura $P$. É. (passe-port à l'étranger) en la esquina superior derecha, y a la expresión au nom du roi.

\section{AU NOM DU ROI,}


El prototipo se emplea también en versalitas, minúsculas e itálicas.

\section{DiX FRANCS.}

Signature du Porteur:

taille d'un mètre

- En elegante modelo gótico, con florida inicial mayúscula, va el vocablo passe-port de la columna izquierda.

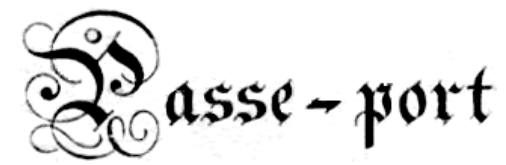

- Queda por último ese complejo molde caligrafiado con bastardillas capitales entrelazadas y engalanadas, en que podía leerse Royaume de France sobre la divisoria matricial.

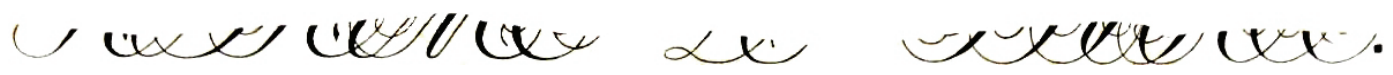

En el texto manuscrito se distinguen dos variantes de bastardilla francesa: una de tendencia recta en la columna de la izquierda, y otra, más caligráfica, inclinada hacia delante y de mayor módulo, en el resto del pasaporte. No obstante, ambas parecen ser de la misma mano.

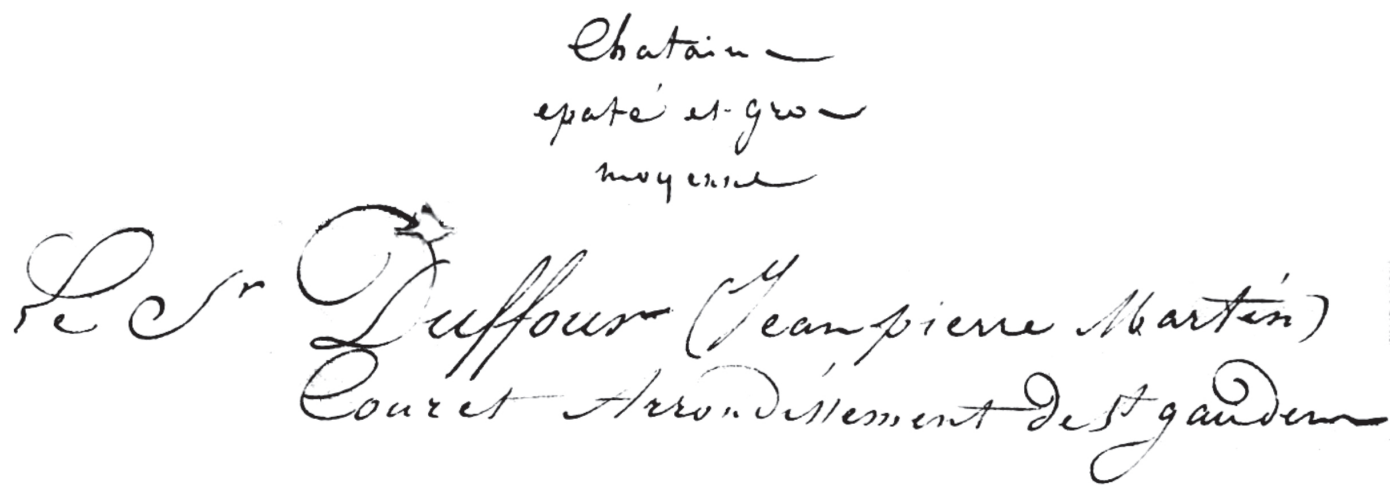

En cuanto a la estructura diplomática propiamente dicha, el formulario pende de tres titulares: la designación del tipo diplomático (Passe-port à l'étranger $)^{56}$, la cláusula de validez temporal (Valable pour un an) y el comienzo de la intitulación ( $A$ u nom du roi).

\footnotetext{
${ }^{56}$ Recordemos que aparece también, abreviada, en la esquina superior derecha: $P . E^{\prime}$.
} 
Continúa el bloque principal con el resto de la intitulatio (Nous, maître des requêtes ${ }^{57}$, préfet de la Haute Garonne ${ }^{58}$ y la disposición con la dirección inserta, consistente en la orden genérica a los funcionarios públicos, franceses o no, de facilitar el tránsito al portador: requérons les autorités civiles et militaires $d u$ royaume, et prions les autorités civiles et militaires des états amis ou alliés de la France, de laisser passer librement le seigneur Duffour, Jean Pierre Martin, natif de Couret, arrondissement de Saint-Gaudens, demeurant a Couret, allant a Madrid, Espagne, et de lui donner aide et protection en cas de besoin. Figuran después una cláusula que especifica el alcance de la autorización (Le présent passeport est valable pendant pour sortir du royaume), y la data: Fait à Toulouse le 21 juin 1836.

En cumplimiento del decreto del 11 de julio de 1810, junto al borde inferior va impresa la tasa, que pasado un cuarto de siglo seguía costando lo mismo: Prix du passe-port: dix francs.

En la columna de la izquierda encontramos los siguientes elementos: el cuerpo gubernativo responsable de pasaportes desde el decreto del 18 de septiembre de 1807 (Police Générale de France); el tipo documental (Passe-port à l'étranger); la cláusula temporal (Valable pour un an); la división administrativa que lo despacha (Département de la Haute Garonne); la nota de asiento en el registro (Registre: número 92); y las señas personales del portador: Signalement: âgé de 33 ans, taille d'un mètre 74 centimètres, (espacio en blanco) pieds (espacio en blanco) pouce, cheveux châtains, front couvert, sourcils châtains, yeux châtains, nez épaté et gros, bouche moyenne, barbe châtaine, menton rond, visage ovale, teint brun coloré. Signes particuliers: (espacio en blanco).

Vemos por tanto que en el conjunto del pasaporte se recogen todos los datos del viajero sugeridos por Bonet de Treyches: departamento y municipio de expedición, fecha, nombre y apellidos del titular, lugar de nacimiento, plazas de origen y destino, y referencias personales.

Los elementos de validación consisten en sellos y suscripciones. Entre los primeros: el real, en seco; el de la Policía, impreso, y el de la prefectura del Alto Garona, estampado en tinta. Las firmas corresponden al propio prefecto Achille Bégé y a un consejero; quien no rubricó, contraviniendo lo legislado, fue el portador Jean Pierre Martin Duffour.

\footnotetext{
${ }^{57}$ Cargo de la administración de justicia asimilable al de auditor.

${ }^{58}$ Se trata de Achille Bégé, gobernador de la provincia desde el 12 de noviembre de 1835 hasta el 28 de julio de 1837.
} 


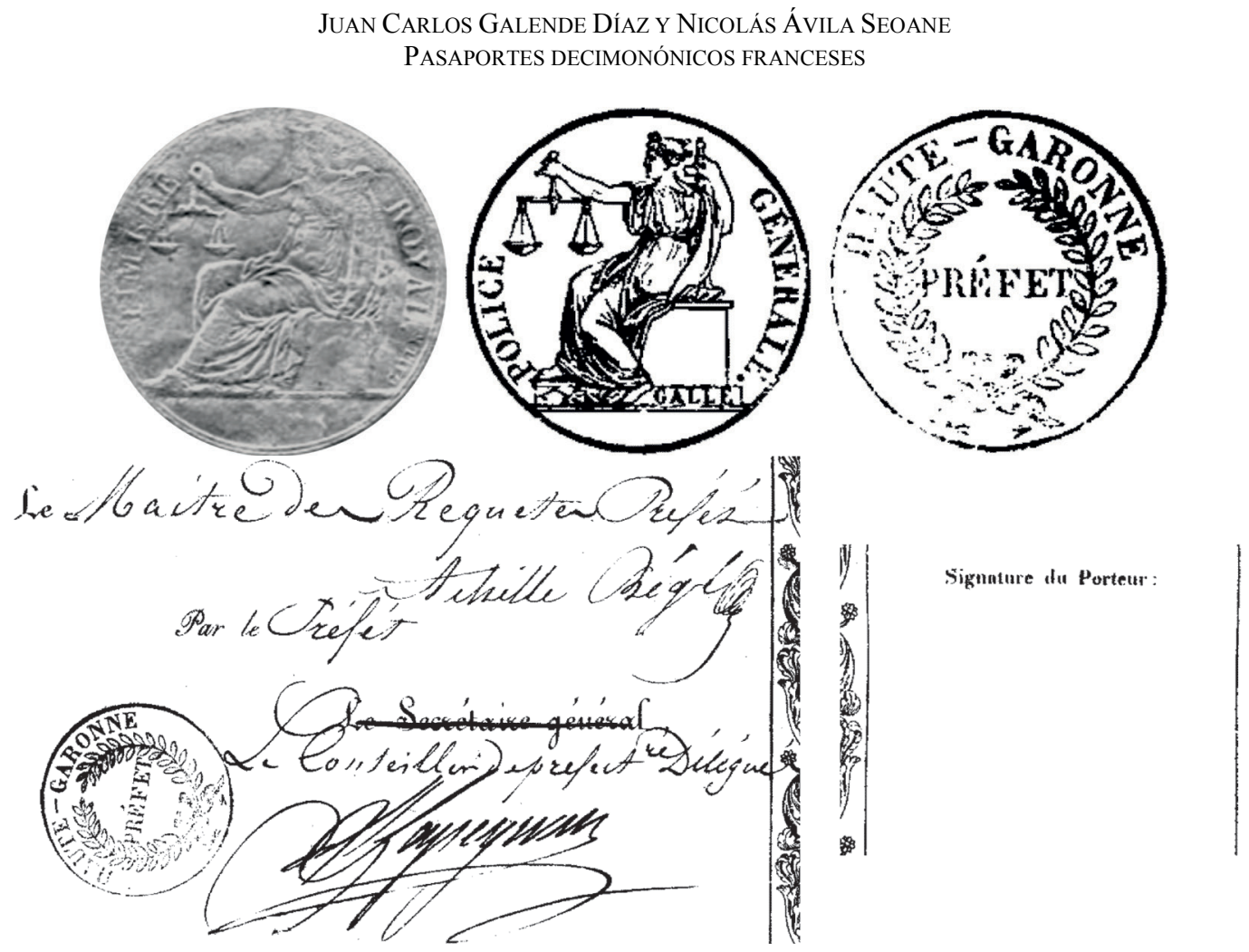

En el margen superior se anotó a mano: Posada de la fonda. Muy probablemente se refiera a la casa toledana de caridad que, apenas doce años después de que, al parecer, se alojara Duffour en ella, describe así Madoz: "Se fundó por el cardenal arzobispo don Francisco Antonio Lorenzana en 1774 con el objeto de que sirviese de fonda o posada a los pasageros que transitasen por el nuevo camino de Madrid a Andalucía, que por convenio con el Gobierno debía dirigirse por esta ciudad, destinando sus rentas al hospital de Santa Cruz; variado el plan de las carreteras, se destinó para acoger y servir de hospicio a los pobres huérfanos y desamparados como dependencia de la gran casa que el mismo arzobispo erigió en el Alcázar" ${ }^{\circ 9}$.

\subsection{Pasaporte de la II República (1852).}

El pasaporte de Escalona, a diferencia del de Toledo, no se despachó mediante talonario sino sobre un bifolio que extendido alcanza los 410 por 550 milímetros y que carece de marcas de agua.

${ }^{59}$ P. MADOZ IBÁÑEZ, Diccionario geográfico-estadístico-histórico de España y sus posesiones de ultramar, vol. XIV, Madrid, 1848, p. 825. 
Juan Carlos Galende Díaz y Nicolás Ávila Seoane

PASAPORTES DECIMONÓNICOS FRANCESES

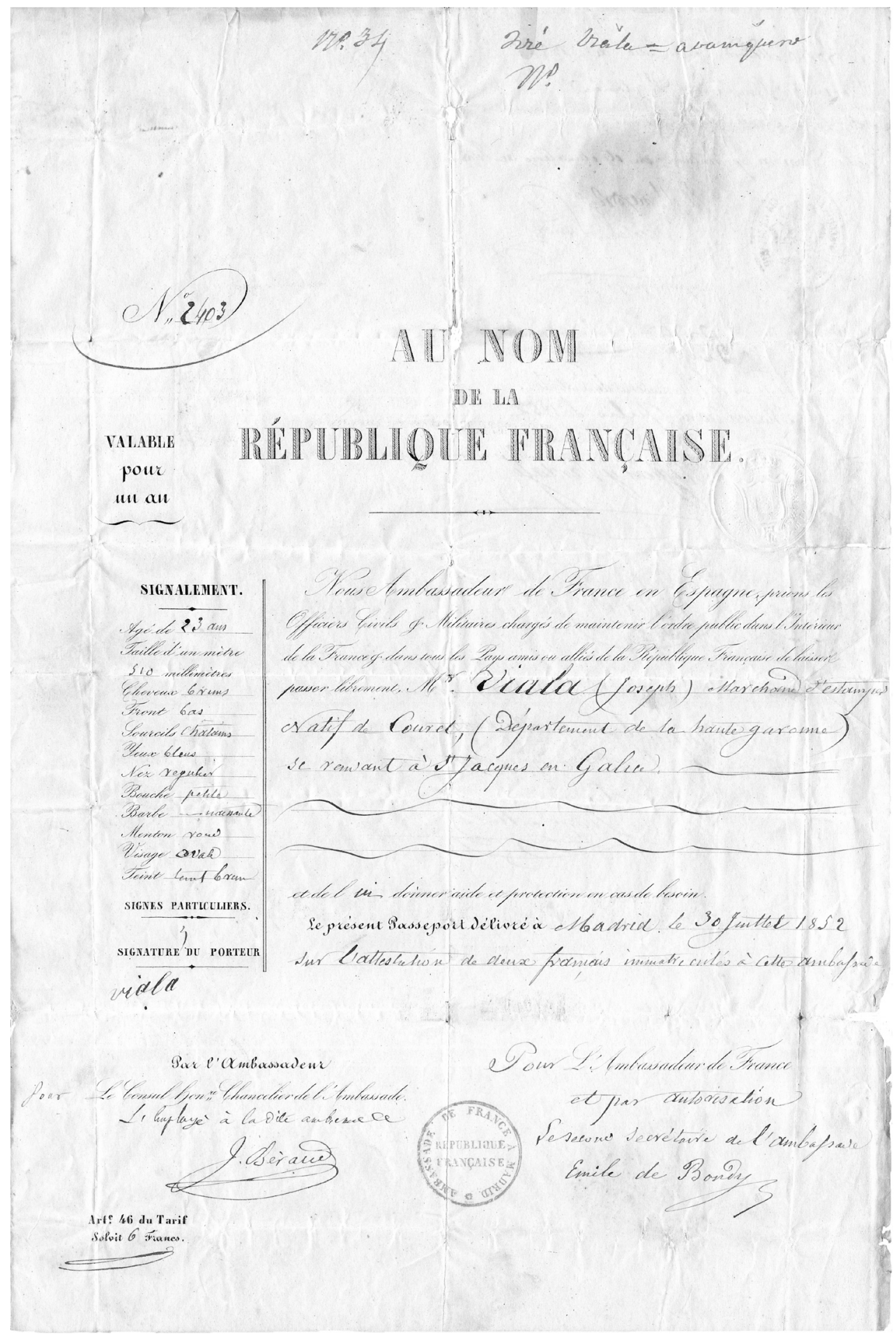

Todo el texto impreso va en color negro y esta vez no hay orla pero sí se mantiene la marginación de la columna de la izquierda, ahora mediante doble línea. 
También aquí se emplean distintas tipografías:

- La letra inglesa vuelve a preponderar, tanto en el cuerpo como en la columna izquierda y en los encabezamientos de las suscripciones. Se aprecia en ella la nota tironiana que suple la conjunción et.

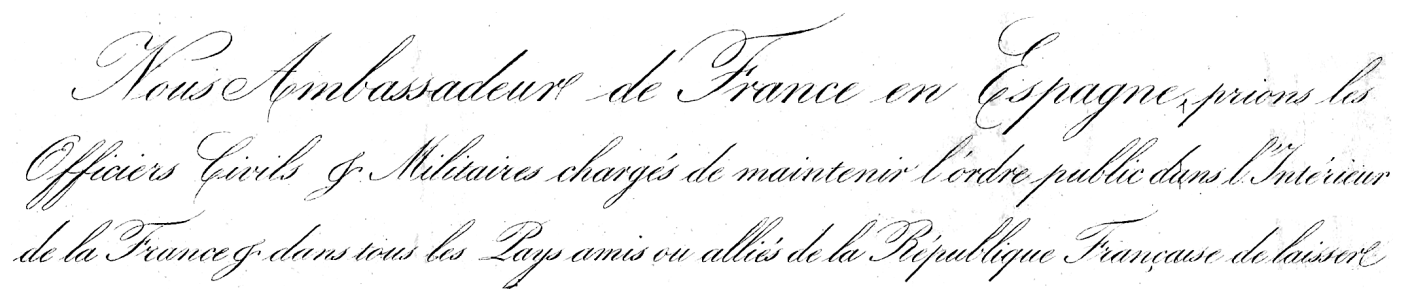

De nuevo la $N$ mayúscula inglesa de la abreviatura para el número de registro tiene poco parecido con la inicial de la intitulación.

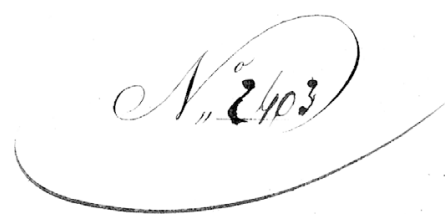

- La redonda puede descubrirse en cuatro oportunidades: en parte de la cláusula de validez (pour un an), al comienzo de la data (Le présent passeport délivré à), en el íncipit de una suscripción (Par l'ambassadeur) y en la tasa (solvit $\mathrm{y}$ francs).

$$
\text { Lepcésent Torospout délivéà }
$$

- Encontramos la humanística capital en los encabezamientos de la columna izquierda y en la primera palabra de la cláusula temporal (valable).

SIGNES PARTLCLLER.

SIGNATURE DU PORTEUR

Con su correspondiente versión minúscula en la cláusula de la tasa.

\section{Art? 46 du Tarif}

Además, en el epígrafe general vemos una variante del modelo capital romano, pero no con los trazos gruesos en negro, sino rellenos de líneas decorativas serpenteantes. 
La parte manuscrita se ajusta a espacios de pauta impresa, en una humanística contemporánea cursiva, con bastante inclinación a la derecha y que se hace más caligráfica en el cuerpo principal, sobre todo las mayúsculas; el apellido Viala aparece especialmente destacado.

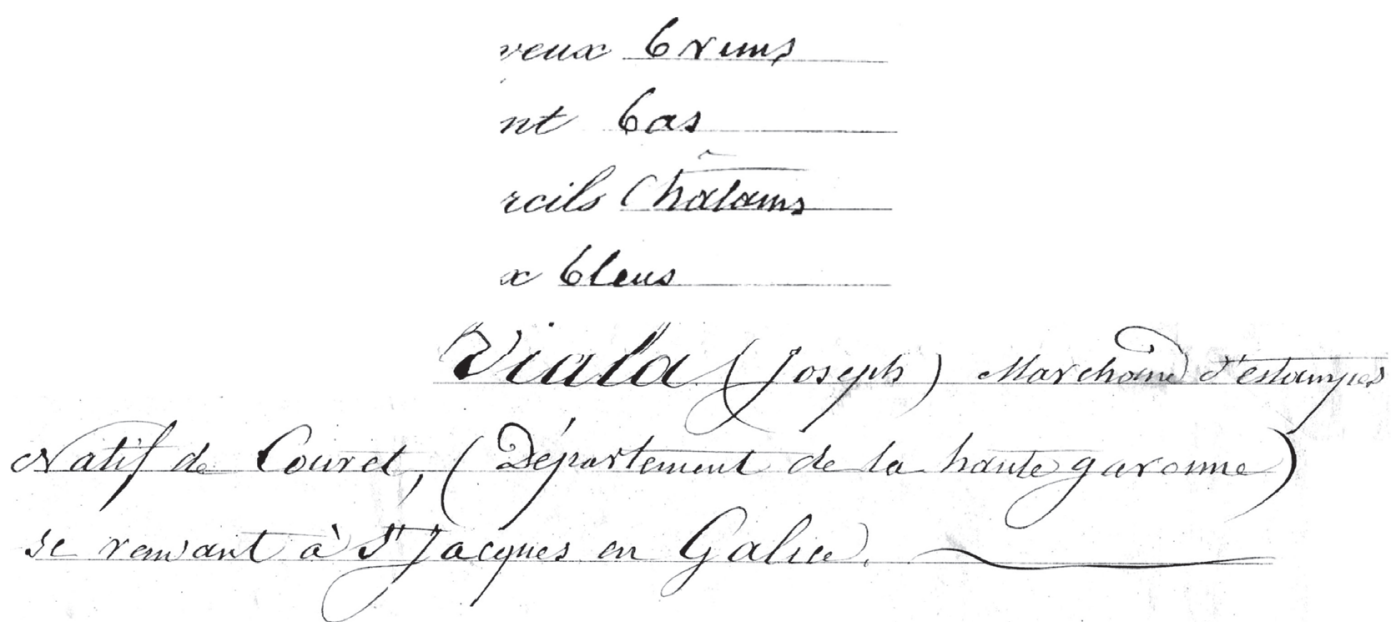

Sin sujetarse a normas de encuadramiento, claro está, figuran las anotaciones cursivas correspondientes a la inscripción del pasaporte en el registro de Escalona.

$$
\operatorname{Min} 2
$$

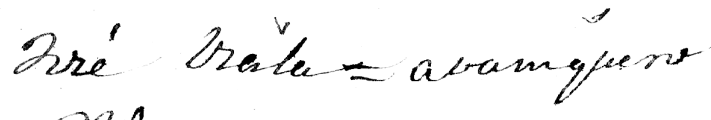

La estructura diplomática empieza por la intitulación, que se reparte entre el encabezamiento ( $A$ u nom de la République Française) y el bloque principal (Nous, ambassadeur de France en Espagne) ${ }^{60}$. A continuación, y nuevamente con

${ }^{60}$ Jacques Aupick, militar francés que ocupó la embajada madrileña menos de dos años. El 30 de julio de 1851 decía El Heraldo: "Nuestro corresponsal de Vitoria nos escribe lo siguiente con fecha del 27: a las doce de la noche de ayer llegó a esta capital el general monsieur Aupik, nombrado embajador de la República Francesa cerca de nuestra Corte, y, después de un breve descanso durante el cual fue cumplimentado por las autoridades para ofrecerle cuantos auxilios 
la directio incluida en ella, aparece la dispositio requiriendo a las distintas autoridades que dejen libre tránsito a Joseph Viala: prions les officiers civils et militaires chargés de maintenir l'ordre public dans l'intérieur de la France et dans tous les pays amis ou alliés de la République Française, de laisser passer librement monsieur Viala (Joseph), marchand d'estampes, natif de Couret, département de la Haute Garonne, se rendant à Saint Jacques en Galice, et de lui donner aide et protection cas de besoin. Siguen luego la fecha (Le présent passeport délivré à Madrid le 30 juillet 1852) y la cláusula corroborativa: sur l'attestation de deux français immatriculés à cette ambassade ${ }^{61}$.

En la columna izquierda encontramos la anotación del registro (Numéro 2403), la cláusula temporal (Valable pour un an) y las señas personales: Signalement: âgé de 23 ans, taille d'un mètre 510 millimètres, cheveux bruns, front bas, sourcils châtains, yeux bleus, nez régulier, bouche petite, barbe naissante, menton roué, visage ovale, teint: teint brun. Signes particuliers: (raya). Al pie, la cláusula de la tasa, también impresa, pero no así el guarismo del importe, que va manuscrito: Article 46 du tarif: solvit ${ }^{62}, 6$ francs.

Garantizan la autenticidad tanto el sello de la embajada, en tinta azul, como las firmas de dos funcionarios de la legación, y, al pie de la sección izquierda, la del propio viajero.

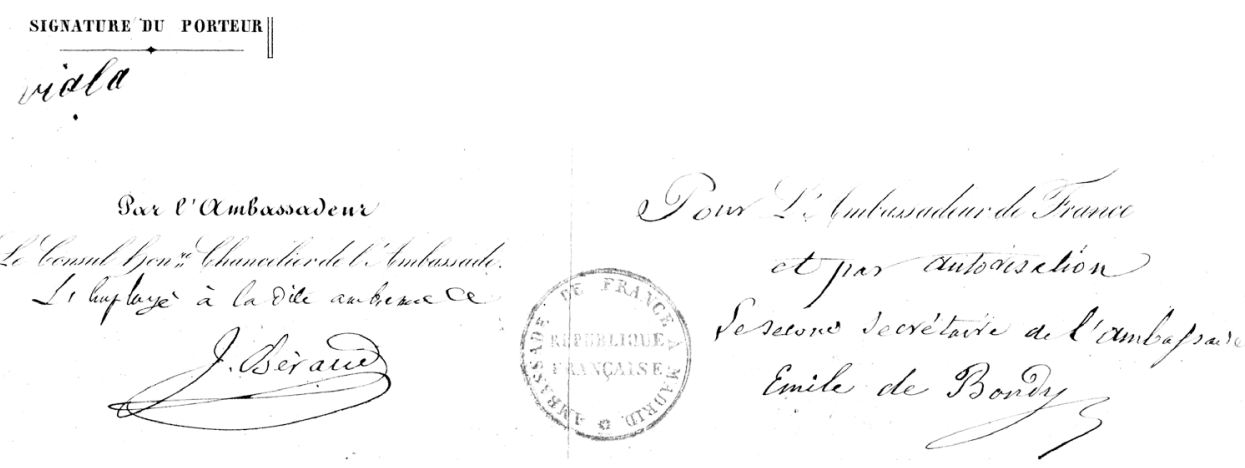

pudiese necesitar, continuó su viaje a Madrid". La noticia de su relevo puede verse en La España del 23 de abril de 1853: "Dice hoy un periódico que el embajador de Francia, general Aupik, ha sido condecorado con la gran cruz de Carlos III, y que ayer salió de esta Corte con dirección a Francia; añade que monsieur de Turgot, su sucesor, debe llegar dentro de muy pocos días".

${ }^{61}$ Así lo exigía el mencionado decreto del 4 de marzo de 1796 a todo francés que quisiera pasaporte. Recordemos que desde el 28 de junio de 1791 era condición inexcusable para extranjeros residentes en Francia o comerciantes que pretendieran abandonar el reino.

${ }^{62}$ Latinismo por 'pagado'. 
Como ya hemos visto, el pasaporte quedó inscrito con el número 34 en el registro municipal de Escalona, anotación que se hizo constar en el extremo superior del documento.

\section{LOS VISADOS.}

Estas breves actas, dispuestas al dorso o en hojas anexas, daban fe entonces, no sólo del paso fronterizo como ocurre en la actualidad, sino también por determinados lugares, especialmente los de pernocta.

Las más sencillas constan únicamente de data tópica y cronológica: Arganda del Rey, 4 de octubre de 1836. Es frecuente añadir, generalmente al principio, una fórmula que deje constancia de la competente inspección: Visto, Presentado, Presentado en tiempo, Presentado a tiempo, Se presentó en tiempo... Otros datos habituales, aparte de este esquema básico, son un número de registro; el destino, tanto final (Jaca, 11 de setiembre de 1836. Visto en esta subdelegación y sigue su ruta a Madrid) como de la siguiente etapa (Zaragoza, 13 setiembre 1836. Presentado y sale el 14 para Calatayud); si ha estado más de un día en el lugar (Esquivias. Presentado en tiempo y ha permanecido hasta oy, 9 de octubre de 1836; Ha permanecido en esta ciudad desde el 11 de octubre último y sale mañana, doce del actual, para Torrijos. Toledo, 11 de enero de 1837, o bien: Presentado en tiempo y sale mañana. Méntrida, 10 de marzo 1837), y tal vez alguna advertencia (Canfranc, 10 de setiembre de 1836. Presentado y lo hará ante el señor gobernador de Jaca). En las localidades más importantes, donde la vigilancia de pasaportes pertenecía a otras instancias ${ }^{63}$, se consigna la institución visadora: Número 1066. Madrid, 30 de julio de 1852. Visto en esta Ynspección de Vigilancia. Sale para Santiago de Galicia. Gratis. Deve de presentarse en el Ministerio de Estado.

El elemento de validación más empleado es la firma del funcionario municipal; en las capitales y lugares con representación diplomática, pueden suscribir gobernadores, cónsules, o sus respectivos delegados. En cuanto a los sellos, en el ejemplar de 1836 sólo hay seis improntas de un total de 53 visados, todas en tinta negra y correspondientes a localidades aragonesas y a la francesa de OloronSainte-Marie. En los tres visados de 1852 se incorporó el sello: de tinta negra en la Inspección de Vigilancia de Madrid y en el Gobierno provincial de Zamora, y seco en el Ministerio de Estado. 41.

${ }^{63}$ J. C. GALENDE DÍAZ, “Fuentes onomásticas: el pasaporte como documento...”, pp. 40- 

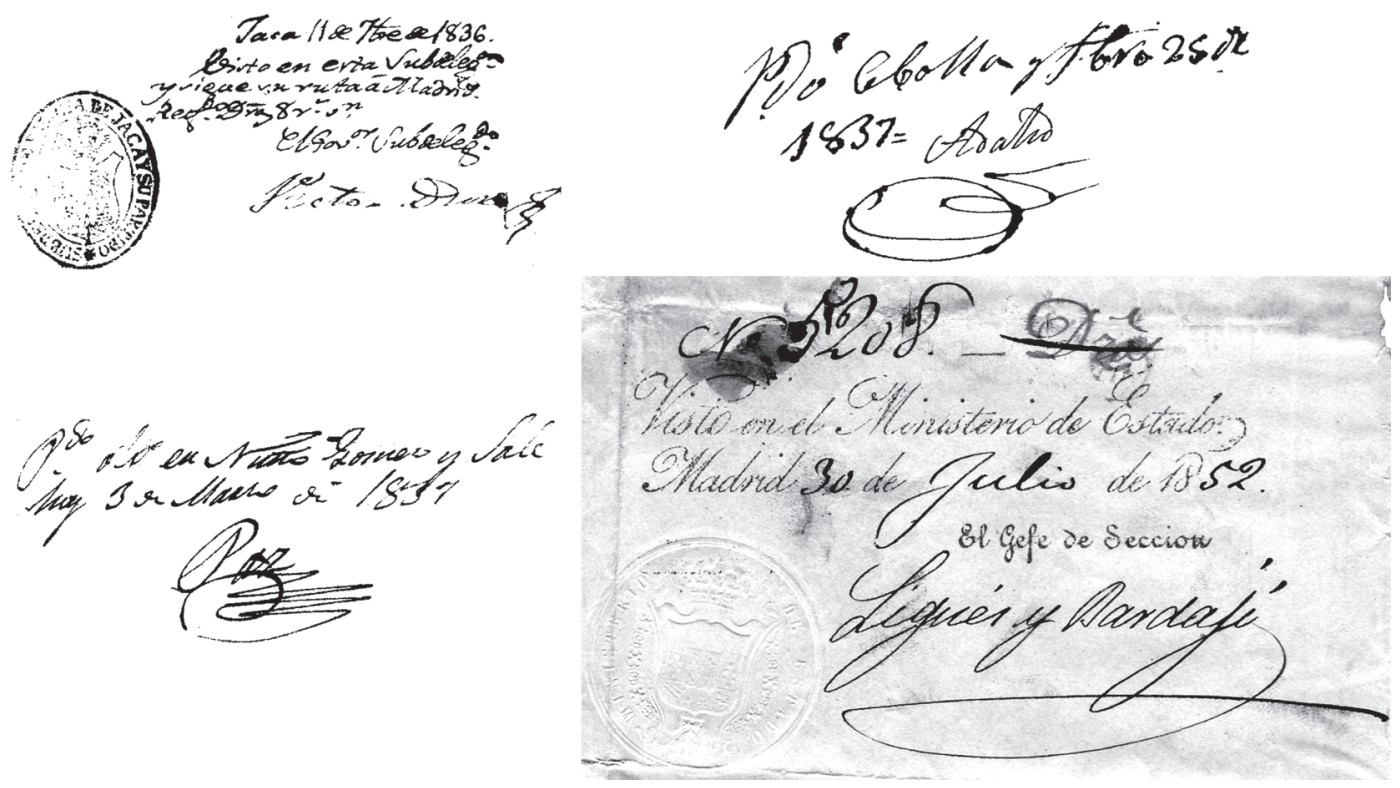

La última imagen respresenta el único visado que se estampó mediante un formulario preimpreso, y completado a mano; el resto son enteramente manuscritos.

Como acabamos de indicar, en el pasaporte del abaniquero Joseph Viala hay tres únicos visados, lo que no permite reconstruir el viaje. Sólo sabemos que lo obtuvo en Madrid el 30 de julio de 1852 con la expresa intención de dirigirse a Santiago de Compostela; que el 30 de octubre pasó por Zamora, declarando esta vez que marchaba a Badajoz, y que el documento acabó, obviamente, en Escalona.

En cambio, el de Jean Pierre Martin Duffour sí deja rastrear detalladamente su itinerario. Y llama la atención ante todo que, aunque el diploma fue despachado en Toulouse el 21 de junio de 1836 para ir a Madrid, no consta tal paradero. Visitó en dos ocasiones Toledo y Talavera de la Reina, pasó también por Escalona, y se le puso el postrer visado en San Martín de la Vega el 13 de marzo de $1837^{64}$.

${ }^{64}$ Pueden verse las siguientes etapas: Oloron-Sainte-Marie ( 8 de septiembre de 1836), Canfranc (10), Jaca (11), Gurrea de Gállego (12), Zaragoza (13 y 14), parador de San Pedro (14), Calatayud (16), Ariza (16), Jubera (17), Algora (18), Taracena (19), Torres de la Alameda (20), Arganda del Rey (20 al 29), Alcalá de Henares (30), San Fernando de Henares (1 de octubre), Vicálvaro (2), Vallecas (3), Arganda del Rey (4), San Martín de la Vega (5), Valdemoro (6), Parla (6), Esquivias (9), Alameda de la Sagra (10), Añover de Tajo (10), Toledo (del 11 de octubre de 1836 al 12 de enero de 1837), Torrijos (12 y 13 de enero), Alcabón (14), Santa Olalla (14), Domingo Pérez (15), Cebolla (16), Talavera de la Reina (17 al 20), La Pueblanueva (24), San Bartolomé de las Abiertas (25), Navalmoral de Pusa (28 y 29), Navahermosa (31), Menasalbas (3 de febrero), Sonseca (7), Toledo (del 8 al 22), Bargas (22), Fuensalida (23), Domingo Pérez (24), Cebolla (25), 


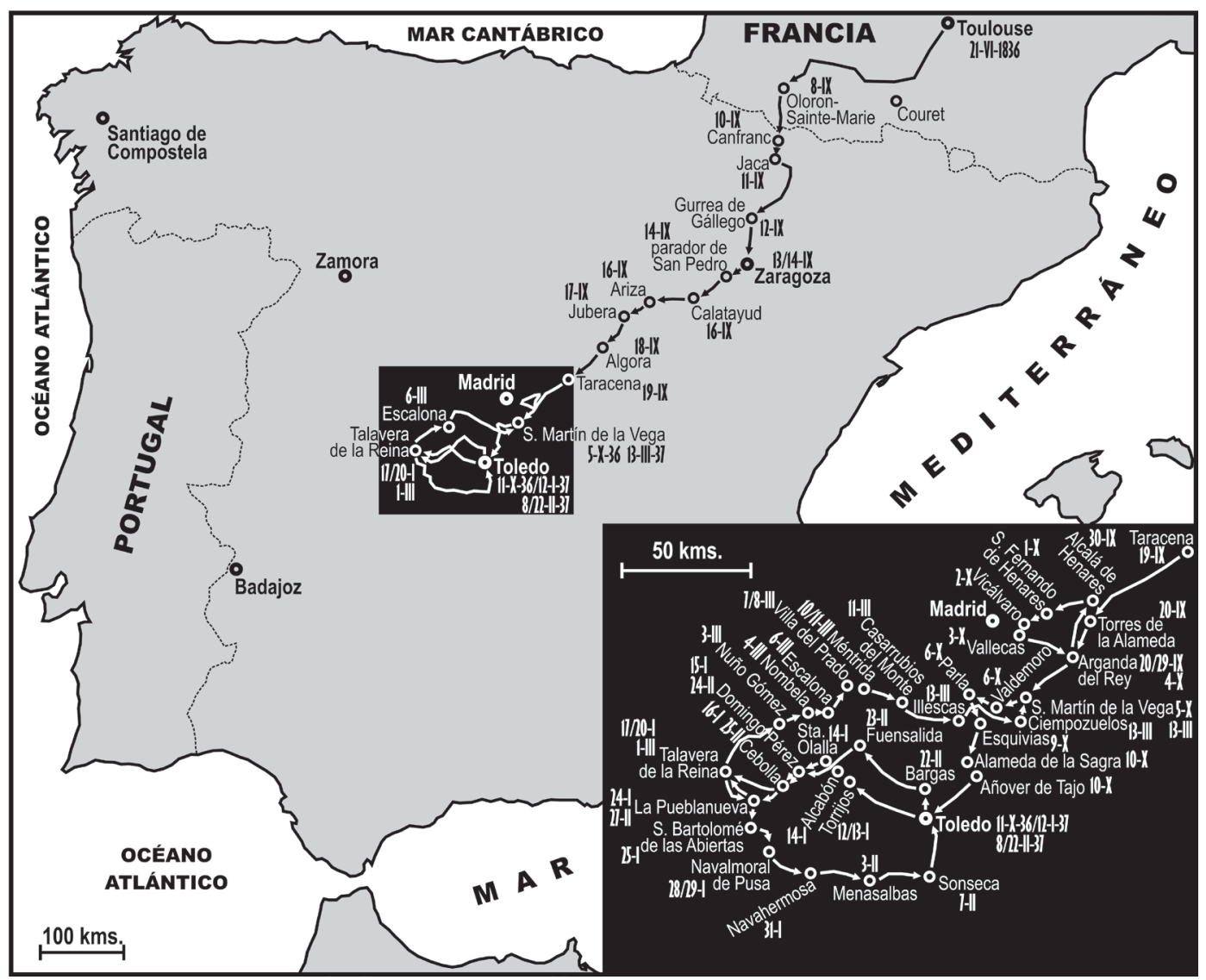

Para concluir queremos destacar cómo, a diferencia de lo que ocurría por ejemplo en España o en el Reino de las Dos Sicilias, las sucesivas autoridades francesas, desde principios del siglo XIX tendieron a unificar los distintos modelos de pasaporte en un solo prototipo centralizado, como garantía de seguridad. Esa mantenida labor resulta especialmente notable si tenemos en cuenta los bruscos vaivenes políticos del país vecino en ese período, pues, desde que estalló la Revolución en 1789 hasta que en 1852 se despacha el pasaporte conservado en Escalona, hubo nada menos que cuatro reyes, dos repúblicas y un emperador.

La Pueblanueva (27), Talavera de la Reina (1 de marzo), Nuño Gómez (3), Nombela (4), Escalona (6), Villa del Prado (7 y 8), Méntrida (10 y 11), Casarrubios del Monte (11), Illescas (13), Ciempozuelos (13) y San Martín de la Vega (13). 